

\section{Katalog Dalam Terbitan}

261

Del Delapan Dekade GPM menanam, menyiram, bertumbuh dan berbuah : d Teologi GPM dalam Praksis Berbangsa dan Bermasyarakat / editor Elizabeth Marantika [et al.].-- Salatiga : Satya Wacana University Press, 2015.

xlii, 698p. ; $23 \mathrm{~cm}$.

ISBN: 978-602-1047-20-0

1. Church and social problems 2. Church and state 3 . Church work 4. Protestant churches--Maluku I. Marantika, Elizabeth II. Protestant Church of Maluku

Cover photo by Kainalu Gaspersz

All rights reserved. Save Exception stated by the law, no part of this publication may be reproduced, stored in a retrieval system of any nature, or transmitted in any form or by any means electronic, mechanical, photocopying, recording or otherwise, included a complete or partial transcription, without the prior written permission of the author, application for which should be addressed to author.

Diterbitkan oleh:

Satya Wacana University Press

Universitas Kristen Satya Wacana

J1. Diponegoro 52-60 Salatiga

Telp. (0298) 321212 Ext. 229, Fax. (0298) 311995

Bekerjasama dengan

Gereja Protestan Maluku (GPM)

Jl. Mayjen DI Panjaitan No. 2

Ambon 97124

Telp. (0911) 342442 


\section{DAFTAR ISI}

Kata Pengantar --- iii

Sambutan Gubernur Maluku --- ix

Sambutan Presiden Uniting Church in Australia - - - xi

Daftar Isi - - - xii

Prolog:

Delapan Dekade Menanam, Menyiram, Bertumbuh dan Berbuah: Refleksi

Sosio-Teologis Historik ber-GPM

John Chr. Ruhulessin--- xvii

Bagian 1: Menjadi Gereja Mandiri

1. 6 September 1935: Sejarah Kemandirian GPM

Johan Saimima - - - 1

2. Dari GPM di Nieuw Guinea Hingga ke GPI di Papua Joice Essuruw-- 12

3. Harta dalam Piring Tua: Jejak Guru Injil Asal Maluku di Tanah Biak, Papua

Elifas Tomix Maspaitella - - 19

4. Pesan Tobat 1960 dan Bukti Keseriusan Gereja Menggumuli

Dunianya

Jozef M.N. Hehanussa -- - 33

Bagian 2: GPM dan Keindonesiaan

1. Tantangan Berteologi bagi GPM di Indonesia

John A. Titaley - - 55

2. Pendidikan Kewargaan bagi Praksis Bergereja

Jakob Tobing-- - 64

3. Politics and Democracy in Christian Perspective

Paul Marshal - - 75

Bagian 3: Eklesiologi GPM: Menjadi Gereja Laut - Pulau

1. Eklesiologi GPM dalam Konteks Masyarakat Kepulauan John Chr. Ruhulessin-- -89

2. Agama Keluarga: Pengenalan Reflektif atas Praksis Kultural Agama Keluarga Masyarakat Lokal Fakfak

Ronald Helweldery--- 103 
3. Gereja Sebagai Keluarga Allah: Eklesiologi Kontekstual Paulus Refialy--- 123

4. Konteks Pengembangan GPM Victor Untailawan--- 141

5. Jemaat Sebagai Sentra Pengembangan Ekonomi Gereja Simon Pieter Soegijono - - - 148

6. Pekerjaan Sosial dan Sumbangannya bagi Diakonia Transformatif Gereja Protestan Maluku

Marthin Jonas Maspaitella--- 169

Bagian 4: Mengerjakan Kontekstualisasi

1. Kesultanan dan Kekristenan: Sekelumit Narasi Menggereja di Utara Rudy Rahabeat--- 179

2. Duan Lolat dalam Perspektif Sosial, Etik dan Teologi Max Chr. Syauta - - 188

3. Jagung dan Spirit Teologi Babar Welhelmus A. Beresaby--- 204

4. E'lodi: Berteologi sambil Berburu di Pedalaman Buru Wendhel Fridholin Lesbassa - - - 219

5. Teologi Ina sebagai Bingkai Pembinaan Keluarga Weldemina Yudit Tiwery--- 235

6. Musik Suling Bambu dalam Pusaran Modernisasi di Gereja Protestan Maluku

Maynard Raynolds Nathanael Alfons-- - 253

7. Teknologi Informatika dan Manajemen Pelayanan GPM Maryo Indra Manjaruni- - - 264

Bagian 5: GPM dalam Praksis Beragama

1. Revitalisasi Tradisi dan Politik Identitas: Ambon dalam Indonesia Steve Gaspersz-- - 273

2. Teologi Orang Basudara: Salam Sarane sebagai Panggilan Agamaagama di Maluku

Markus Takaria--- 289

3. Ketimpangan Relasi Agama dan Adat di Maluku

Yance Z. Rumahuru--- 302

4. Pemaknaan Yesus dalam Budaya Pela Menuju Kristologi Masyarakat Maluku

Yohanes Parihala---313

5. Islam, Kristen dan 'Dunia Lain' di Maluku

Sumanto Al Qurtuby--- 325 
6. Damai di Negeri Salam-Sarane: Perspektif Seorang Anak Piara Muslim

Lailatul Fitriyah -- - 339

Bagian 6: GPM dan Pengembangan Pendidikan di Maluku

1. Pergumulan Pendidikan Indonesia dan Peranan Gereja Willi Toisuta-- -353

2. Membangun Jemaat dengan Pendidikan yang Bermutu Thomas Pentury-- - 371

3. Timbulnya Dualisme dalam Sistem Pendidikan di Maluku Tengah Cornelis Adolf Alyona - - - 383

4. Pendidikan Perdamaian dan Praksis Pendidikan Teologi yang Kontekstual

Nancy Novitra Souisa - - - 382

5. Merangkai yang Terurai dan Patah: Implementasi Perdamaian melalui Pemberdayaan Perempuan dan Anak Jeany Elna Mahupale - - 405

Bagian 7: GPM di Tengah Pusaran Oikoumene dan Perdamaian

1. Tahuri Persaudaraan Telutih: Perspektif Teologis Seram Selatan George M. Likumahwa--- 423

2. Janji Damai di Batas Negeri: Praksis Berteologi di Lease Zakarias Sapulette- - - 433

3. Meneroka Ruang-ruang Oikoumene Baru: Sebuah Penjelajahan Trisno S. Sutanto-- - 447

4. GPM dalam Pusaran Gerakan Oikoumene di Indonesia Henrek Lokra - - - 464

5. Gerakan Oikoumene, Gereja dan Masa Depannya di Maluku Daniel Wattimanela--- 473

6. Masyarakat Berkeadaban di Jalan Susastra dan Seni Rudy Fofid - - 486

7. Mengawal Simpul-simpul Perekat Antar Umat Beragama di Maluku Tenggara Barat: Catatan Reflektif Ricardo Rikumahu--- 497

Bagian 8: Bergumul di Laut dan Gunung: Praksis Bergereja di Klasis dan Jemaat

1. Mengelola Keesaan Bersama GMIH Odhie Ririmasse--- 505 
2. Bergereja Bersama Basudara Muslim: Pengalaman Bersama di Seram Bagian Timur

Lodewik W. Laisila dan Fridolin R. Kwalomine--- 512

3. Berseru Kepada Pohon Tumbang: Refleksi Teologis dalam Krisis Lingkungan di Seram Utara

Jondry Paays - - 525

4. GPM dan Advokasi Lingkungan

Simson M. Reskir-- -536

5. Perempuan Kei dalam Citra Bergereja: Dinamika dan Tantangan di Kepulauan Kei

Adonia Titiahy-Leiwakabessy--- 552

6. Namaku Indonesia, Mataku Memandang Australia: Menjadi GPM di Beranda Depan Negara

Daniel Zwingly Wutwensa--- 560

7. Beribadah di Rumah Ternak: Pengalaman Penggembala di Klasis Leti Moa Lakor

Melky Timisela--- 576

8. Quo Vadis Benjina?

Peter Robert Manuputty-- - 586

9. Problematik Kesehatan Masyarakat dan Implikasinya bagi Jemaat Johanis Fritzgal Rehena--- 593

Bagian 9: GPM dalam Pandangan dan Harapan Pimpinan Umat Beragama

1. Percikan Harapan Islam kepada GPM H. Idrus E. Toekan--- 607

2. Gereja Protestan Maluku: Pendapat dan Harapan Gereja Katolik Keuskupan Amboina

Mgr. Petrus Canisius Mandagy---615

3. Delapan Dekade Gereja Protestan Maluku di Mata Umat Buddha W. Jauwerissa-- -623

Bagian 10: Membaca Alkitab pada Delapan Dekade GPM

1. Biarkan Anak-anak itu Datang Kepada-Ku: Tafsir Markus 10:13-16 dari Sudut Pandang Pengasuh

Bace Pattiselano- - 627

2. Mengasuh Anak di Pulau-pulau

Mercy Lekransy--- 640

3. Jangan Menghakimi Perempuan itu: Membaca Yohanes 8:1-11 dari Pengalaman Pendampingan ODHA

Rosa Pentury--- 651 
4. Hibrid(isasi) Gereja di Era Postkolonial: Membaca Konflik di Gereja Korintus bersama Homi K. Bhaba

Ekaputra Tupamahu---662

Epilog:

Perlukah Pesan Tobat Jilid Dua?

John Chr. Ruhulessin---681

Para Penulis --- 689 


\title{
EKLESIOLOGI GPM DALAM KONTEKS MASYARAKAT KEPULAUAN
}

\author{
---John Chr. Ruhulessin --- \\ [Ketua Sinode GPM 2005-2010, 2010-2015]
}

\section{Pengantar}

Pokok eklesiologi mengandung aspek teologis, dogmatik, sosiologi tan antropologi. Karena itu perlu kajian yang integratif terhadap seluruh aspek kehidupan masyarakat/umat, baik dalam konteks kebudayaannya yang kadang primordial, sambil melakukan transformasi terhadapnya maupun konteks budaya universal/am. Beberapa perspektif yang penting dikemukakan, antara lain:

Pertama, eklesiologi harus menjadi acuan teologi-sosial terhadap jati diri (integritas) gereja, dan arah operasional kepada gereja dalam mengembangkan berbagai sistem bergereja (sistem berjemaat, kepemimpinan, institusionalisasi/organisasi, pelayanan, pemberdayaan). Jika ditempatkan sebagai bagian dari kerygma, maka eklesiologi memberi inspirasi ke dalam rumusan pengakuan iman/ajaran gereja.

Kedua, pada sisi praksis, eklesiologi menerangkan mengenai cara dan tujuan beradanya gereja di tengah-tengah dunia. Sebuah eklesiologi mendeskripsikan hal-hal mendasar tentang untuk apa gereja ada di dalam dunia, mengapa gereja lahir. Itu berarti eklesiologi kontekstual berdimensi heurestik (kesejarahan), dalam arti menempatkan gereja di dalam konteks kemenjadian dan kehidupannya (gereja yang berkarya).

Ketiga, eklesiologi adalah tanggapan kritis dan reposisi gereja tentang dan di dalam konteks gumulnya. Dengannya gereja mengembangkan cara pandang (point of view) dan cara paham (thought) tentang dirinya, dan tanggung jawabnya di dunia.

Keempat, eklesiologi adalah kenyataan bahwa gereja itu berada di dalam dunia; lahir sebagai hasil proses berbudaya masyarakat di dalam konteksnya masing-masing; mengalami pertemuan yang intens dalam relasi interpersonal dan antarmasyarakat, serta mengembangkan berbagai karunia (kharis) sebagai bagian dari peran Roh Kudus di dalam hidup umat. Artinya, eklesiologi menuntun kerja teologi kontekstual yang tiada henti. 
Karena panggilan Allah kepada gereja berlangsung dalam hidup gereja di dunia, maka eklesiologi adalah diskursus intens antara gereja dengan dunia. Dengannya gereja meresapi karya Tuhan di dalamnya sebagai suatu "persekutuan yang kudus" (the holy communion).

\section{Reorientasi Eklesiologi GPM}

Mengapa eklesiologi GPM? Pertanyaan ini sama pentingnya dengan pertanyaan kelompok sosial yang menamakan dirinya 'eklesia' di abad ke-2. Pada abad ke-2, pertanyaan itu menjadi perlu sebab kelompok 'eklesia' itu baru merupakan suatu kelompok sosial yang berciri asosiasi. Hubungan mereka dengan kekaisaran Romawi dan faksi-faksi politik yang ada kala itu, sering tegang. ${ }^{1}$

Dalam perkembangannya, pada zaman Bapa-bapa Gereja ( The Holy Fathers) pergumulan tentang eklesiologi menjadi makin penting, dan ada pula sebagai sebuah apologia di dalam konteksnya. Berbagai tuduhan, yang mengalamatkan gereja ibarat kelompok tahyul (hatheria), atau kaum kriminal, dan bahkan kaum marginal yang tidak terdidik dan cenderung berperilaku buruk menjadi dasar dari apologia itu. ${ }^{2}$ Isu pokok dalam pergumulan awal itu berkisar pada isu-isu teologis-dogmatik, atau bentukbentuk afirmasi Kristen tentang Yesus dan kuasa Allah. Sampai pada Abad Pertengahan, gereja dihadapkan pada perkembangan ilmu pengetahuan dan filsafat yang banyak sekali membentuk cara pandang orang tentang Tuhan dan gereja.

Konsili am gereja-gereja yang berujung pada skisma gereja-gereja Timur dan Barat nyaris tidak terhindarkan. Kita belajar dari berbagai konsili dan gerakan Reformasi Luther dan Calvin, sebagai realitas yang menerangkan bahwa rumusan eklesiologi pada zaman mana pun dibangun dari realitas gereja dalam masyarakat. ${ }^{3}$

Di Amerika Latin, pergumulan tentang jati diri gereja (eklesiologi), berlangsung juga secara intens. Kolonisasi, kemiskinan dan perbudakan rasial menjadi isu pokok di sana. Teolog seperti Gustavo Gutiérrez melancarkan berbagai protes di dalam kerangka teologi pembebasan - yang jauh hari telah didengungkan Martin Luther King. ${ }^{4}$ Dengan cara itu, Gutiérrez membangun suatu critical reflection on praxis, yang menjadikan teologi-eklesiologi suatu refleksi kritis manusia terhadap dirinya pada basis prinsipnya, sadar akan dirinya, sadar akan elemen-elemen konseptualnya. ${ }^{5}$

Bentangan peta pemikiran itu dimaksudkan untuk mengatakan bahwa isu-isu di dalam eklesiologi juga merupakan isu publik yang harus diwacanakan sebagai suatu persoalan gereja dan iman. ${ }^{6}$ Karena itu ketika kita membincangkan eklesiologi GPM, berbagai isu teologis dan publik perlu diidentifikasi agar eklesiologi kita menjadi sesuatu yang 'fresh', selalu 
mengalami penyegaran, dan dialektika kontekstualisasi tiada henti. Saya memberi catatan kritis di sini, sebab saya merasa bahwa selama ini diskursus eklesiologi masih terbelit oleh isu-isu afirmatif yang rata-rata adalah warisan teologi Barat (Western heritage) dan elaborasi konteksnya masih perlu İperkental agar 'rasa Maluku-nya' makin mengental pula.

Eklesiologi GPM mesti secara jeli memperhatikan beberapa hal, antara lain:

- Rumusan gerejawi seperti tertuang di dalam Tata Gereja GPM, bahwa 'kita yang dahulu umat Allah, telah dipanggil menjadi umatNya, ...keluar dari kegelapan kepada terang-Nya yang ajaib' (1 Pet. 2:9).

- Kesadaran bahwa GPM adalah hasil evangelisasi badan zending Belanda (NZG), tanpa menafikan sejarah penginjilan pada zaman kolonial (Portugis, Belanda, Inggris, Jepang).

- Kesadaran kontekstual tentang keberadaan GPM di bumi Seribu Pulau (aspek kepulauan), dalam basis-basis sub-kultur (multikulturalisme) yang membentuk GPM sebagai salah satu gereja Suku

- Relasi dengan Salam dalam realitas pluralisme di Maluku

- Kehadiran GPM di Indonesia (dalam seluruh dinamika sejarah bangsa, termasuk polemik separatisme dan nasionalisme tahun 1950)

- Keberadaan GPM sebagai bagian dari gereja-gereja di dunia, dan warga dunia (universalitas)

- Tanggapan GPM terhadap berbagai problem sosial di Maluku, Indonesia dan Dunia

\section{Pengakuan Diri Gereja/GPM}

Mengakui bahwa keberadaan GPM sebagai hasil penginjilan badan sending Belanda berarti menempatkan GPM di dalam sejarah am gerejagereja di dunia. Artinya, evangelisasi sebagai proses pertemuan umat dengan malitas injil atau kabar damai sejahtera atau kabar kebaikan, berlangsung melalui pekerjaan-pekerjaan kudus yang dilakukan orang-orang kudus (para pelabar Injil). Ini adalah suatu kesadaran sejarah tentang bagaimana gereja menjadi atau terbentuk. Dengan begitu, kita tiba pada refleksi kritis bahwa:

Pertama, pekabaran injil berlangsung melalui proses pertemuan (encounter), adaptasi, akulturasi, akomodasi, dan bahkan dalam segi tertentu İfusi atau pun invasi. Di Maluku, corak difusif dan invasif hampir tidak bisa Ėelakkan. Bahkan harus diakui bahwa para tenaga lokal (Guru Injil) lebih invasif terhadap berbagai sistem kebudayaan kita yang telah dicap gelap atau penyembahan berhala. Akibatnya, pertemuan Injil dan kebudayaan (adat) 
berlangsung secara dikotomis. Gereja berusaha meruntuhkan berbagai praktik adat. $^{7}$

Gereja telah memposisikan diri sebagai penjaga kerygma dan harus mencegah berbagai praktik lain selain praktik-praktik ritual di dalam gereja. John S. Spong menyatakan bahwa masalah ibadah, liturgi, dan kemudian Tuhan, menjadi pokok persoalan gereja-gereja sepanjang masa. ${ }^{8}$

Tidak bisa disangkali bahwa GPM lahir di dalam ketegangan Injil dan kebudayaan yang intens. Ada kecurigaan misiologis dimana gereja memandang hampir semua bentuk ritus adat sebagai representasi dunia gelap dan penyembahan berhala. Pengakuan itu pun turut mendasari suatu rumusan gerejawi dalam Pembukaan Tata Gereja dan juga "Pesan Tobat 1960 ".

Sampai pada persoalan itu, hal yang fundamental adalah reduksi makna Injil dan adat. Terminologi "mengadatkan Injil" dan "menginjilkan adat" adalah terminologi misiologis yang sudah menempatkan Injil dan adat pada dua titik silang yang hampir sulit diterjemahkan secara teologis. Karena itu dalam hal ini," gereja perlu membangun berbagai upaya kontekstualisasi melalui proses-proses akulturasi, adaptasi dan indigenisasi Injil.

Bevans cukup membantu dalam diskusi ke arah itu secara metodologis. Saya berpendapat bahwa upaya ke arah itu harus dilakukan secara intensif agar kita bisa memberi jawaban-jawaban teologis terhadap persoalanpersoalan lokal kita dalam public sphere yang luas. Disertasi saya, "Etika Publik: Menggali Dari Tradisi Pela di Maluku" adalah sebuah usaha kecil yang perlu terus dikembangkan, terutama untuk melihat persoalan-persoalan gerejawi dan teologi secara mendasar. ${ }^{10}$

Hal pokok yang hendak ditegaskan di sini bahwa kita perlu membangun berbagai usaha teologis secara sistematis untuk menghasilkan suatu eklesiologi yang lebih "berasa Maluku" atau bercorak GPM. Hal itu telah menjadi kebutuhan ke arah perubahan dan pengembangan GPM.

Kedua, identitas GPM sebagai salah satu gereja suku di Indonesia adalah suatu citra lokal yang mesti diterjemahkan secara baru. Menyebut GPM sebagai gereja suku bisa mengarahkan kita pada corak primordialisme mondial yang akhirnya membuat GPM sangat eksklusif. Sebetulnya gejala ke arah itu sudah bisa kita lihat dalam menguatnya corak pandangan "jemaatsentrisme". Hal ini sulit kita hindari, sebab jemaat-jemaat kita itu lahir di dalam negeri-negeri yang homogen secara struktural.

Secara eklesiologi, identitas gereja suku itu melahirkan corak pengorganisasian yang berbasis pada teritorial suku/sub suku. Artinya, secara struktural GPM hanya ada di Provinsi Maluku. Kita ingat persis di era 1980an, dengan berbesar hati kita harus memandirikan Jemaat GPM di Papua menjadi Gereja Protestan Injili (GPI) Papua. Padahal jauh sebelum itu, misi 
GPM berlangsung sampai di tanah Papua. Wawasan teritorialisme itu makin mempertebal identitas gereja suku pada GPM.

Wawasan teritorialisme itu pula yang membentuk corak parokhialisme-teritorial sebagai suatu corak berjemaat di GPM. Dalam arti itu, struktur jemaat-jemaat GPM menyatu di dalam struktur negeri sebagai teritori sosiogenealogis dimana jemaat-jemaat itu lahir. Fakta ini menjadi makin unik dalam jemaat-jemaat yang mencakup dua atau lebih negeri (mis: Uweng Gabungan di Klasis GPM Taniwel, Jelestra - Jerili, Lesane, Trana, juga Bumei-Sefluru di Klasis GPM Masohi, dan di lain tempat). Di sisi lain, pada sebuah negeri besar yang secara sosiologis makin kompleks (mis: Passo), sulit untuk dimekarkan karena dimensi kesatuan negeri itu sebagai suatu teritori sosio-genealogis. Akan menjadi berbeda dengan jemaat-jemaat besar di kawasan perkotaan yang telah dimekarkan dan akan terus dimekarkan.

Di sisi lain, pascakonflik sosial, wawasan teritorialisme itu pun menjadi masalah serius pada beberapa jemaat yang berbasis teritori sosiogenealogis seperti itu, misalnya Poka, Rumah Tiga. Warga jemaatnya terserak di berbagai tempat đi Kota Ambon, dan masih tetap memiliki ikatan emosional yang kuat dengan jemaat asalnya, walau belum atau sudah tidak kembali lagi ke teritori jemaat asalnya itu. Ini adalah kasus-kasus seputar masalah eklesiologi, secara struktural, yang perlu dilihat dan dikaji kembali terkait dengan corak berjemaat GPM.

Identitas gereja suku membuka ruang yang luas bagi berkembangnya corak-corak lokal, atau berbagai bentuk kearifan lokal, pranata sosial-budaya, yang bisa memberi sumbangan ke dalam corak berjemaat atau eklesiologi dan juga teologi kita di Maluku.

Saya berpendapat, keputusan untuk menjadi gereja yang mandiri pada 1935 adalah suatu keputusan monumental GPM; suatu keputusan sejarah yang membuat GPM benar-benar menjadi gereja yang sejati. Artinya, Roh Allah turut bekerja di dalam pengambilan keputusan itu. Ini bukan sebuah keberanian semata tetapi suatu tindakan sejarah untuk membangun kualitas misi gereja di Maluku. Sebagai keputusan monumental, mestinya kita tidak sekadar membangun asumsi bahwa sejak saat itu GPM mandiri secara finansial, artinya tidak lagi bergantung kepada Indische Kerk.

Keputusan monumental mesti menjadi momentum untuk mandiri secara teologis, eklesiologis dan misiologis agar 'rasa Maluku'lebih mengental dalam teologi dan eklesiologi kita.

Mewarisi corak teologi dan eklesiologi Calvinis adalah sebuah pilihan untuk berada di dalam komunitas am gereja-gereja di dunia. Tetapi -menjadi GPM yang benar-benar memiliki citarasa Maluku adalah panggilan menjadi gereja yang kontekstual-fungsional di dunia. Karena itu, identitas 
gereja suku kini mesti dimengerti sebagai cara membangun sebuah gereja yang menjadi milik dan berpihak kepada masyarakat (a public church).

\section{Konteks Kepulauan}

Secara sosiologis, masyarakat continental memiliki struktur-struktur sosial dan konsentrasi pertumbuhan yang spesifik. Pada daerah kontinen, kota menjadi sentrum perubahan. Corak urban merupakan suatu titik perubahan kawasan continent. Sistem ekonomi merkantilisme berubah secara cepat melalui pembangunan infrastruktur baru. Industri pun makin bervariasi, bukan hanya industri pertanian tetapi juga industri raksasa baru, sampai pada penciptaan teknologi maju.

Secara politis, koordinasi wilayah-wilayah dalam kawasan continent berlangsung secara cepat. Kota sebagai pusat, memiliki strukturstruktur sosial-politik yang mapan, dengan kecenderungan sentralisasi yang sangat kuat. Tidak heran, jika pada saat Calvinisme muncul, masyarakat terstruktur dalam kerajaan-kerajaan (monarkhi) dengan gaya otoriterianisme yang kuat. Pola-pola demokrasi baru muncul pada zaman kemudian, setelah sistem monarkhi di banyak tempat jatuh.

Pola koordinasi itu kemudian berkembang di dalam gereja melalui satuan-satuan asosiasi pada berbagai lembaga gerejawi. Apa yang kemudian dikenal sebagai Sinode adalah pengendali jalur koordinasi dengan jemaat. Satuan-satuan organisasi di bawah Sinode terhimpun melalui berbagai bentuk kerjasama dan asosiasi tadi. Gaya sentralisasi memang menjadi hal yang penting, sebab dalam kawasan continent, struktur kekuasaan ada di pusat dan dikendalikan melalui berbagai posisi yang hierarkhis dan cenderung paternalistik. ${ }^{11}$

Berada di kawasan kepulauan Maluku, memberi kepada kita tantangan baru untuk melihat bagaimana pola koordinasi pelayanan berlangsung dalam hubungan antarwilayah.

Selama ini kita mengakui bahwa sistem Presbiterial Sinodal adalah suatu sistem organisasi gereja bercorak Calvinis. Sistem tersebut sudah kita polakan secara fleksibel, dengan melembagakan Klasis secara struktural. Pada posisi middle line itu, Klasis menjadi vital dalam mempercepat koordinasi antarwilayah. Dalam konteks bergereja di kepulauan Maluku, aspek koordinasi antarwilayah mesti mendapat prioritas, sehingga Klasis harus terstruktur untuk menjaga jaringan koordinasi gereja.

Hal-hal itu perlu dikemukakan dalam rangka membuat peta struktur eklesiologi GPM dalam konteks kepulauan secara dinamis. Betapa sensitivitas kepulauan mesti menjadi dasar asumsi dan refleksi eklesiologi itu sendiri. 
Berikut ini beberapa tipikal kepulauan Maluku untuk merenungi lagi model eklesiologi GPM, yakni:

Pertama, dalam konteks kepulauan Maluku, jemaat-jemaat GPM enstruktur di dalam sub-kultur pada negeri dengan pranata dan simbol hulaya masing-masing. Satuan-satuan sub-kultur ini adalah bagian dari saraan kultur yang lebih luas, misalnya Lease, Ambon, Seram Selatan, Seram Aarat, Seram Timur, Seram Utara, Maluku Tenggara (Kei Besar dan Kei Fecil), Lemola, Babar, Kisar, Aru, Halmahera, Ternate, Tobelo, Bacan, Obi, Auru, dll. Seberapa besar atau kecil kita membagi kawasan sub-kultur tadi, maka seperti itu pula karakteristik dan tipikal jemaat-jemaat GPM. Hal ini aftalah suatu kenyataan di dalam eklesiologi kepulauan di GPM.

Kedua, Sejauh unsur-unsur budaya yang universal ada pada setiap sub-kultur, tetapi dari sisi ide-ide sosial dan pranata-pranata tertentu, mermasuk ide persaudaraan ('orang basudara') yang terbingkai dalam berbagai Inanata, seperti pela-gandong, kakawai, larvul-ngabal, merupakan sistemsistem sosial-budaya yang bisa menjadi suatu senyawa tertentu di dalam arak hidup berjemaat.

Sistem-sistem kebudayaan lain yang terkait dengan pola kerja sama, misalnya masohi, maren, sosoki, dll, bisa pula menjadi kerangka pengertian dan kerjasama untuk menggairahkan sistem-sistem pelayanan gereja. Selain itu, mekanisme komunalitas seperti soa, mata rumah, marga, Tiga Batu Tungku, adalah material-material lain mengandung nilai-nilai bersama (common value). ${ }^{12}$

Ketiga, dimensi solidaritas masyarakat pulau-pulau, dengan tipikal jang sedikit bervariasi antara masyarakat pegunungan dengan masyarakat pesisir menjadi penting untuk mengembangkan karakter bergereja yang meliputi umat, pelayan dan kelembagaan. Daya mobile yang sedikit berrariasi antara masyarakat pegunungan dan pesisir pun menjadikan dimensi sclidaritas itu suatu aspek yang perlu dipahami sesuai tipikal masyarakat ämaksud.

Keempat, ketersebaran wilayah pelayanan di pulau-pulau, dengan bentangan laut yang luas menjadi penting untuk melihat mekanisme koordinasi antarwilayah dalam rangka meningkatkan kesadaran bersama sebagai anggota Tubuh Kristus, atau kesadaran bersama sebagai gereja Tuhan Ei Maluku. Realitas ini perlu diperhatikan untuk melihat aspek-aspek kelembagaan dan pola organisasi.

Secara geografis dan sosio-ekonomi, salah satu implikasi dari ketersebaran itu ialah tersusunnya jemaat-jemaat tertentu pada pusat kebijakan (policy center), baik di level provinsi maupun kabupaten/kota. Banyak jemaat ada di pedalaman dan pelosok yang sulit dijangkau/terisolasi. Implikasi praksisnya ada pada pertumbuhan ekonomi jemaat-jemaat, 
rendahnya angka harapan hidup, serta terbatasnya kapasitas sumber daya manusia. Sedangkan di jemaat-jemaat di perkotaan, terjadi penumpukan sumber daya manusia di tengah berbagai kemajuan yang dialami.

Ketersebaran itu menjadi indikasi kuat bahwa proses bertumbuh dan berkembang bersama ke arah kemajuan perlu dikoordinasi oleh gereja. Relasi kemitraan dalam kerangka bertumbuh dan berkembang bersama sudah saatnya dipoles dan di-redesign agar kawasan pusat pengembangan bisa menjadi penyangga bagi kawasan periphery.

Kelima, jemaat-jemaat di pusat kebijakan kemudian menjadi jemaat-jemaat yang kompleks yang ditandai oleh makin banyaknya bentuk peran sosial, dan pembagian peran sosial yang hampir tidak berimbang antara rasio penduduk dan jumlah bidang kerja. Selain itu, pembauran antaretnis adalah gejala sosial suatu masyarakat kompleks yang tidak terelakkan, disusul bertumbuhnya budaya populer atau budaya urban di perkotaan.

Dari sisi gerejawi, kompleksitas itu melahirkan jemaat-jemaat khusus dan jemaat-jemaat kategorial/profesional atas alasan etnik (mis: Cina - Jemaat Hok Im Tong, Kota Ambon), maupun basis profesi, yang umumnya TNI-Polri (selain di Kota Ambon, ada pula di Klasis Masohi dan SBB Piru). Jemaat-jemaat ini bertumbuh di dalam desakan budaya urban yang terus tinggi, seiring perkembangan infrastruktur ekonomi dan juga instalasi militer di pusat-pusat kota itu.

Sekadar menjadi catatan kita bahwa jemaat-jemaat khusus dan kategorial, misalnya di Ambon, memiliki tipikal yang beragam. Tidak semua warga jemaat khusus Hok Im Tong adalah etnis China. Demikian pun perubahan wajah demografi di beberapa jemaat kategorial TNI-Polri, seperti Pniel Bentas, Getsemani Piru, dimana penduduk sipil pun telah menetap di situ.

\section{Realitas Sosial}

Perubahan konteks sosial di Maluku dan Indonesia, bahkan dunia perlu menjadi bahan kajian eklesiologi GPM itu sendiri.

Isu-isu seputar kemiskinan, keterisolasian, keterbelakangan, menjadi isu eklesiologis yang terkait dengan pelaksanaan "amanat panggilan gereja". Menjadi church for the poor merupakan suatu rumusan eklesiologi yang cukup digandrungi dewasa ini. Terminologi ini telah melahirkan suatu pemahaman baru bahwa amanat agung itu bukan hanya seperti termaktub dalam Matius 28:19-20, dengan perintah "membaptis dan mengajar" yang dalam banyak hal bermakna proselitisme dan bernuansa triumfalistik.

Perluasan paradigmatik amanat agung itu membuat gereja menjadi makin fungsional. Bagi gereja, tanggung jawab memanusiakan manusia adalah dimensi Injil Kristus yang terbuka bagi dunia. Rumusan-rumusan 
biblis seperti Lukas 4:18,19 atau Matius 25:35-40, adalah suatu paradigma amanat agung yang mengedepankan kesejahteraan, pembebasan, pemerdekaan, pemulihan, kemanusiaan.

Paradigma yang lebih maju lagi terkait dengan pertanyaan mengenai "siapakah sesamaku manusia". Pertanyaan ini penting dalam konteks pluralisme di Maluku dan Indonesia. Panggilan sosial gereja di dalam masyarakat majemuk adalah untuk membangun kesadaran pluralisme dan ketahanan sosial umat. Dalam rangka itu, integrasi dan harmoni sosial-politik menjadi suatu harapan ideal dan penampakan koinonia dan oikumene semesta gereja-gereja di Maluku, Indonesia dan dunia.

Paradigma church with others merupakan suatu langkah maju dalam desain eklesiologi gereja. Paradigma ini sama sekali tidak bertendensi sinkretis - walau sebenarnya kita tidak usah menjadi takut dan naif terhadap sinkretisme. John Hicks mengatakan bahwa gereja-gereja tidak bisa menyangkali realitas bahwa kita hidup di dalam suatu lingkaran kebudayaan (cultural borders), dan bersamaan dengan itu pun di dalam lingkaran gerejawi (ecclesiasticâl borders). Dua lingkaran itu menempatkan gereja dalam satu lingkaran baru yakni lingkaran agama-agama (religious borders), yang dalam banyak hal bersinggungan pada sisi misi/dakwah. Tetapi entah seseorang lahir dari orang tua Muslim, lalu menjadi Muslim, atau dari orang tua Kristen dan menjadi Kristen, atau Yahudi dan menjadi Yahudi, iman kita yang berbeda-beda itu hanyalah suatu fenomenologi. Realitas terbesar dan aktual yang tidak bisa dielakkan adalah lingkaran-lingkaran tadi bukanlah justifikasi dari suatu pertentangan yang hakiki. ${ }^{13}$

Paradigma ini menunjuk pada keberpihakan gereja pada kesesamaan dan kebersamaan. Gereja, dengan jalan itu, menampakkan panggilannya untuk menyampaikan kabar baik kepada dunia dan manusia. Gereja menjadi alat pendamaian dan kasih kepada dunia dan manusia; gereja menjadi alat pembangun bangsa.

Di dalam pengertian itu, eklesiologi harus pula merupakan suatu wujud kesadaran berbangsa dari gereja (GPM). Eklesiologi apa pun yang kita susun perlu mengakui keberadaan kita di dalam bangsa. Beradanya gereja di dalam bangsa adalah suatu bentuk tindakan Tuhan yang menempatkan gereja ¿i dalam sejarah dan peradaban bangsa. Karena itu, gereja yang ada di dalam bangsa menjadi agen moralitas bangsa (bnd. Luk. 9:1-6; Yoh. 17:4,20-21; Roma 13:1-6, dll).

Dengan demikian, relasi gereja-negara pun mesti dilihat secara ḋalektis. Demokrasi Indonesia menempatkan relasi gereja-negara secara setara, sampai pada dimensi yang instrumental yakni kesamaan hak setiap warga negara, tanpa memandang perbedaan agama, suku, ras, etik, bahasa, dan perbedaan latar belakang sosial lainnya. Karena itu gereja bukan 
subordinasi dari negara, dan bukan pula bagian struktural dari negara (dalam Departemen Agama). Dialektika gereja-negara memberi kepada gereja suatu posisi peran khusus dalam rangka turut memberi fungsi kritik profetik kepada negara.

Hal ini tidak bisa diterjemahkan dalam arti gereja secara institusional saja, tetapi gereja secara organis (manusia). Eklesiologi dalam arti ini terkait dengan tanggung jawab warga gereja dalam negara dan bangsa. Itu adalah eklesiologi yang fungsional.

Apakah isu-isu seperti HIV/AIDS, narkoba, dll.; itu pun sudah menjadi isu eklesiologi bagi GPM? Ketika kita menjadikannya isu eklesiologi, berarti kita pun mesti membuka diri pada realitas kaum gay/homoseksual, transgender dan mewacanakannya sebagai bagian dari realitas berjemaat kita. Selain itu, kasus-kasus kekerasan seksual, kekerasan kepada anak, dan bentuk-bentuk kekerasan lain telah membuat sebagian jemaat kita diperlakukan secara diskriminatif.

Fakta-fakta itu perlu dikemukakan untuk melihat bahwa sebagian warga jemaat kita hidup dalam garis marjinal dan bahkan diskriminasi yang tajam. Jika ini menjadi suatu fakta yang penting bagi eklesiologi, berarti gereja perlu menyatakan sikap melawan berbagai tindakan asusila dan kekerasan itu. John Spong melihat isu seperti homoseksual sebagai suatu kenyataan yang tidak bisa dihindari gereja-gereja di Amerika dan Australia. Bahkan kaum homoseksual pun memerlukan suatu wadah gereja dan sentuhan pelayanan gereja itu pula. Spong juga mengkritik bagaimana diskriminasi telah terjadi terhadap mereka, ataupun kekerasan terhadap anak atas anasir-anasir tafsir kitab suci yang berat sebelah. ${ }^{14}$ Mungkin ini belum menjadi fakta sosial yang permanen di Maluku, tetapi sejauh menjadi konsumsi dan perhatian gerejawi, adalah perlu melihatnya sebagai realitas sosial di seputar pergumulan eklesiologi GPM. Di masa depan hal ini mungkin akan menjadi suatu persoalan yang sudah mesti dipikirkan secara serius.

\section{Eklesiologi yang Kontekstual-Fungsional}

- Saya hendak mengakhiri paparan ini dengan menegaskan kembali beberapa hal substansial dalam rumusan gerejawi kita yang telah ada, sebagai bahan perenungan ke depan.

Kita perlu berpedoman pada Tata Gereja GPM sebagai sandaran konsepsional yang juga memuat pernyataan sejarah kemenjadian GPM.

Saya tidak akan mengulangi rumusan-rumusan definitif, afirmatif, dan dogmatik itu lagi. Yang hendak saya tegaskan ulang adalah pergeseran titik tolak dalam pembaruan teologi GPM, seperti dirumuskan dalam PIP/RIPP GPM 2005-2015. Fokus pada pemberdayaan jemaat, membuat 
GPM kini mengacu pada penguatan karakter, penguatan eklesiologi, fakta pluralisme masyarakat, krisis multidimensional - di Maluku dan Indonesia, kesadaran kebangsaan, penguatan kesejahteraan dan keadilan serta penguatan kepedulian etik dan moral. Titik tolak pembaruan itu mengarah pada profil gereja yang meliputi profil keumatan, profil kelembagaan dan profil pelayan. ${ }^{15}$

Dalam PIP/RIPP tersebut, kita telah berusaha membangun komitmen bergereja untuk membangun suatu visi ke arah terwujudnya orangorang beriman yang berkualitas, terbuka, maju, mandiri dalam segala aspek kehidupan; memiliki rasa kebersamaan, kesetiakawanan dengan orang lain; dan peranserta gereja dalam mendirikan tanda-tanda kerajaan Allah yakni cinta kasih, keadilan, kebenaran, kemanusiaan, perdamaian, keutuhan ciptaan dan kesejahteraan bagi seluruh ciptaan Allah. ${ }^{16}$

Dari visi itu, lingkup pelayanan gereja meliputi semua (a) warga gereja: anak, remaja, pemuda, perempuan, laki-laki, orang dewasa dan orang rua-lanjut usia; (b) jemaat teritorial dan kategorial di desa dan kota; (c) kelompok fungsional;" ketegorial dan fungsional; (d) anggota masyarakat yang lemah - miskin dan terpinggirkan (kaum marginal); (e) gereja-gereja dan denominasi lain; (f) umat beragama lain, dan (g) alam ciptaan Allah. ${ }^{17}$

Jika ruang lingkup itu dipahami dalam struktur eklesiologi, berarti eklesiologi GPM bukanlah suatu rumusan afirmatif melainkan suatu cara pandang tentang tugasnya dalam praksis. GPM bukanlah sebuah gereja yang terperangkap dalam rumusan dogma dan ajaran, melainkan gereja yang berjumpa dan ditemukan di dalam ruang sosialnya.

Menjadi gereja yang fungsional atau membangun suatu eklesiologi yang fungsional adalah bagian dari cara GPM menjalankan amanat agung dari TUHAN di dalam dunia (lokalitas dan universalitas). Suatu eklesiologi yang fungsional kiranya dibangun dengan memperhatikan:

- Panggilan Gereja yang am/rasuli -dimensi biblis

- Jatidiri gereja yang am dan rasuli (akar-akar tradisi, dan perlu transfọrmasi, transliterasi)

- Dinamika sejarah dan tujuan beradanya gereja di dunia, terutama di dalam konteks yang partikular -dalam hal ini GPM

- Dinamika konteks dan tipikal masyarakat setempat (aspek lokalitas dan kontekstual)

- Konteks bangsa dimana gereja ada dan berkarya (termasuk relasi gereja-negara)

- Konteks global dimana gereja mewujudkan panggilannya

Semoga di usia GPM yang telah delapan dekade ini, kita bisa membangun suatu pemahaman eklesiologi yang merasuki seluruh ruang 
pelayanan gereja dan membentuk kematangan umat dalam menjadi gereja yang hidup.

Aku menanam,

Apolos menyiram,

Tetapi Allah yang memberi pertumbuhan.

\section{Daftar Pustaka}

Gutiérrez, Gustavo, 1983, We Drink from Our Own Wells, NY, Maryknoll: Orbis Books.

A Theology of Liberation: History, Politics and Salvation, Revised Edition with a New Introduction, translated and edited by Sister Caridad and John Eagleson, NY, Maryknoll: Orbis Books, 1994

Hicks, John, 1999, "Whatever Path Men Choose Is Mine", and "A Philosophy of Rêligious Pluralism", dalam Christianity and Plurality: Classic and Contemporary Readings, edited by. Richard J. Plantinga, Malden, Massachusetts: Blackwell Publ. Inc.

Kee, Howard Klark, et.al (eds.), 1994, Christianity: A Social and Cultural History, second edition, NJ: Prentince Hall, 1998Wagner, Walter H., After the Apostles: Christianity in the Second Century, Minneapolis: Fortress Press.

Kooiman, 1989, W.J., Marthin Luther, terj. P.S. Naipospos, Jakarta: BPK Gunung Mulia, 1989

Maspaitella, Elifas Tomix, 2001, "Tiga Batu Tungku: Analisa SosioBudaya dan Refleksi Teologis Terhadap Kerjasama Antarinstitusi di Ema Pulau Ambon", Tesis Magister pada Program Magister Sosiologi Agama, UKSW, Salatiga.

Maspaitella, Elifas Tomix, 2008, "Persoalan Seputar Injil dan Adat di GPM: •Perang Tanding Pandangan Dunia", dalam Pendeta di Tegah Pusaran Zaman: Biografi Pdt. (Em.) Dominggus Louhenapessy, editor. Rudy Rahabeat \& Hery Siahay, Ambon: LeSMMu.

Radjawane, A.N., 2008, "Menghargai Kelebihan Orang Lain", dalam Pendeta di Tegah Pusaran Zaman: Biografi Pdt. (Em.) Dominggus Louhenapessy, editor. Rudy Rahabeat \& Hery Siahay, Ambon: LeSMMu.

Ruhulessin, John, 2005, Etika Publik: Menggali dari Tradisi Pela di Maluku, Salatiga: Satya Wacana University Press. 2008, Jelajah Pemikiran Etika Menuju Jalan Baru Etika Kristen di Indonesia, editor. Elifas Tomix Maspaitella. 
Sekretariat Umum Sinode GPM, 2006, PIP/RIPP GPM 2005-2015, Ambon.

Spong, John Shelby, 1998, Why Christianity Must Change or Die: A Bishop Speaks to Believers in Exile, NJ: HarperSanFansisco, Harper Collins Publ. , 2001, A New Christianity for A New World: Why Traditional Faith is Dying and How A New Faith is Being Born, NJ: HarperSanFrancisco.

2005, The Sins of Scripture: Exposing the Bible's Texts of Hate to Reveal the God of Love, NJ: HarperSanFansisco, Harper Collins Publ.

Van den End, Th., 2003, Harta dalam Bejana, Sejarah Gereja Ringkas, Jakarta: BPK Gunung Mulia.

Wilken, Robert L., 1984, The Christians As the Romans Saw Them, New Haven \& London: Yale University Press.

\section{Catatan Akhir:}

${ }^{1}$ Baca Robert L. Wilken, The Christians As the Romans Saw Them, New Haven \& London: Yale University Press, 1984, hlm. 10,22 dyb

${ }^{2}$ Baca Ibid., lihat juga Walter H. Wagner, After the Apostles: Christianity in the Second Century, Minneapolis: Fortress Press, 1994, hlm. 67-223; John Shelby Spong, A New Christianity for A New World: Why Traditional Faith is Dying and How A New Faith is Being Born, NJ: HarperSanFrancisco, 2001, hlm. 201 dyb; atau juga Howard Klark Kee, et.al (eds.), Christianity: A Social and Cultural History, second edition, NJ: Prentice Hall, 1998, hlm. 7-112.

${ }^{3}$ Lih. W.J. Kooiman, Marthin Luther, terj. P.S. Naipospos (Jakarta: BPK Gunung Mulia, 1989), hlm. 51-67, 163-178.

4 Lih. Gustavo Gutiérrez, A Theology of Liberation: History, Politics and Salvation, Revised Edition with a New Introduction, translated and edited by Sister Caridad and John Eagleson, NY, Maryknoll: Orbis Books, 1994; idem, We Drink from Our Own Wells, NY, Maryknoll: Orbis Books, 1983

${ }^{5}$ Lih. John Ruhulessin, Jelajah Pemikiran Etika Menuju Jalan Baru Etika Kristen di Indonesia, editor. Elifas Tomix Maspaitella, 2008, hlm. 45.

${ }^{6}$ Lih. John Ruhulessin, Etika Publik: Menggali dari Tradisi Pela di Maluku (Salatiga: Satya Wacana University Press, 2005).

${ }^{7}$ Lih. Elifas Tomix Maspaitella, "Persoalan Seputar Injil dan Adat di GPM: Perang Tanding Pandangan Dunia" dalam Pendeta di Tegah Pusaran 
Zaman: Biografi Pdt. (Em.) Dominggus Louhenapessy, editor. Rudy Rahabeat \& Hery Siahay, Ambon: LeSMMu, 2008, h.197-210

${ }^{8}$ John Shelby Spong, ibid., h.201

9 Bnd. Th van den End, Harta dalam Bejana, Sejarah Gereja Ringkas, Jakarta: BPK Gunung Mulia, 2003, h.260; bnd pula kesaksian A.N. Radjawane (penulis naskah Pesan Tobat) "Menghargai Kelebihan Orang Lain", dalam Pendeta di Tegah Pusaran Zaman: Biografi Pdt. (Em.) Dominggus Louhenapessy, editor. Rudy Rahabeat \& Hery Siahay (Ambon: LeSMMu, 2008), hlm. 33, 34.

${ }^{10}$ Ruhulessin, Etika Publik.

${ }^{11}$ Kee, et.al (eds.), ibid., hlm. 113-182.

${ }^{12}$ Lih. Elifas Tomix Maspaitella, Tiga Batu Tungku: Analisa SosioBudaya dan Refleksi Teologis Terhadap Kerjasama Antarinstitusi di Ema Pulau Ambon. Tesis Magister pada Program Magister Sosiologi Agama, UKSW, Salatiga, 2001.

13 John Hicks, "Whatever Path Men Choose Is Mine" and "A Philosophy of Religious Pluralism" dalam Christianity and Plurality: Classic and Conternporary Readings, edited by. Richard J. Plantinga (Malden, Massachusetts: Blackwell Publ., 1999), hlm. 324, 325.

${ }^{14}$ John Shelby Spong, Why Christianity Must Change or Die: A Bishop Speaks to Believers in Exile (NJ: HarperSanFancisco Publ., 1998), hlm. $7 \mathrm{dst}$; atau Idem, The Sins of Scripture: Exposing the Bible's Texts of Hate to Reveal the God of Love (NJ: HarperSanFancisco, 2005), hlm. 113-144.

${ }^{15}$ Lih. Sekretariat Umum Sinode GPM, PIP/RIPP GPM 2005-2015, Ambon, 2006, hlm. 3.

${ }^{16}$ Ibid., hlm. 4.

${ }^{17}$ Lih. Sekretariat Umum Sinode GPM, ibid., hlm. 6. 